Article

\title{
Structural and Electronic Properties of Different Terminations for Quartz (001) Surfaces as Well as Water Molecule Adsorption on It: A First-Principles Study
}

\author{
Xianchen Wang ${ }^{1,2,3}(\mathbb{D})$, Qin Zhang ${ }^{2,3,4, *}$, Xianbo $\mathrm{Li}^{2,3,4}$, Junjian $\mathrm{Ye}^{2,3,4}$ (1) and Longjiang $\mathrm{Li}^{2,3,4}$ \\ 1 College of Resources and Environmental Engineering, Guizhou University, Guiyang 550025, China; \\ xcwang1990@163.com \\ 2 College of Mining, Guizhou University, Guiyang 550025, China; xbli1990@163.com (X.L.); \\ lawyerlj922713@163.com (J.Y.); mnlljiang@163.com (L.L.) \\ 3 National \& Local Joint Laboratory of Engineering for Effective Utilization of Regional Mineral Resources \\ from Karst Areas, Guiyang 550025, China \\ 4 Guizhou Key Laboratory of Comprehensive Utilization of Non-Metallic Mineral Resources, \\ Guiyang 550025, China \\ * Correspondence: qzhang@gzu.edu.cn; Tel.: +86-851-8829-2081
}

Received: 6 December 2017; Accepted: 5 February 2018; Published: 9 February 2018

\begin{abstract}
Structural and electronic properties of Si termination, O-middle termination, and O-rich terminations of a quartz (001) surface as well as water molecule adsorption on it were simulated by means of density functional theory (DFT). Calculated results show that the O-middle termination exposing a single oxygen atom on the surface is the most stable model of quartz (001) surface, with the lowest surface energy at $1.969 \mathrm{~J} \cdot \mathrm{m}^{-2}$, followed by the O-rich termination and $\mathrm{Si}$ termination at $2.892 \mathrm{~J} \cdot \mathrm{m}^{-2}$ and $2.896 \mathrm{~J} \cdot \mathrm{m}^{-2}$, respectively. The surface properties of different terminations mainly depend on the surface-exposed silicon and oxygen atoms, as almost all the contributions to the Fermi level $\left(E_{F}\right)$ in density of states (DOS) are offered by the surface-exposed atoms, especially the $\mathrm{O} 2 \mathrm{p}$ state. In the molecular adsorption model, $\mathrm{H}_{2} \mathrm{O}$ prefers to adsorb on the surface $\mathrm{Si}$ and $\mathrm{O}$ atoms, mainly via $\mathrm{O}_{1}-\mathrm{H}_{1}$ bond at $1.259 \AA$ and $\mathrm{Si}_{1}-\mathrm{O}_{\mathrm{w}}$ at $1.970 \AA$ by Van der Waals force and weak hydrogen bond with an adsorption energy of $-57.89 \mathrm{~kJ} \cdot \mathrm{mol}^{-1}$. In the dissociative adsorption model, the $\mathrm{O}$-middle termination is hydroxylated after adsorption, generating two new $\mathrm{Si}-\mathrm{OH}$ silanol groups on the surface and forming the $\mathrm{O}_{\mathrm{w}} \mathrm{H}_{2} \cdots \mathrm{O}_{4}$ hydrogen bond at a length of $2.690 \AA$, along with a large adsorption energy of $-99.37 \mathrm{~kJ} \cdot \mathrm{mol}^{-1}$. These variations in the presence of $\mathrm{H}_{2} \mathrm{O}$ may have a great influence on the subsequent interfacial reactions on the quartz surface.
\end{abstract}

Keywords: electronic properties; quartz; water molecule adsorption; density functional theory

\section{Introduction}

Quartz is an important mineral that has wide applications as a raw material in various fields in industry, such as glass, ceramics, and medicine [1-3]. It is the main component mineral of a series of important mineral resources such as siliceous phosphate ore, iron ore, tungsten ore, fluorite, and mica. Flotation is a widely accepted way to separate and utilize these ore resources based on the difference in wettability (hydrophilic and hydrophobic characteristics at a macroscopic-level) of the mineral particle surfaces by froth, which occurs at the interfaces of solid/air/water in the solution [4,5]. Furthermore, the surface chemical activities of minerals in flotation has a close relationship with its surface structure and properties. Therefore, it is crucial to accurately determine the mineral surface structure so that one can understand its interactions well with other molecules, such as water [6], calcium hydroxyl ions [7], and flotation reagents $[5,8,9]$. 
The surface structures and characteristics of quartz crystal have been investigated extensively using traditional means of analysis technologies, such as X-ray diffraction [10], scanning electron microscope [11], and photoelectron spectrum [12], but these studies have failed to offer more detailed surface structural and electronic properties at the level of electron and atom due to the limited resolution or accuracies of the above analysis methods. Even though atomic force microscopy can provide an overall characterization of the surface topography of a quartz (001) surface on a nanometer scale [13] and offer images of synthetically grown-quartz (0001) surfaces [14], it still fails to further determine the detailed microstructure of the exposing atoms on surface. With the development of quantum chemistry theory and computer technology, DFT calculations based on first principles have been widely used in acquiring the micro-structural information of various minerals with high accuracy, such as clay minerals [15-17], iron minerals [18], and sulfide minerals [19,20]. These studies have provided a theoretical basis for the quantitative interpretation of mineral properties.

In going from a bulk crystal to a surface, the atoms along the cleaved plane experience a loss of coordination, and this can manifest in new features in the electronic structure, as demonstrated in DFT studies in the literature [21,22]. Many researchers have focused on the surface properties of cleaved quartz using computational methods, and the consensus is that the (001) surface is the thermodynamically predominant plane [23-26]. Meanwhile, even for the single (001) plane, there are many possible terminations that are distinct in terms of the identity and number of terminal atoms. When the surface is in contact with an aqueous phase, water adsorption and dissociation processes can further modify the surface structure. As structure and composition affect reactivity, different surface terminations can thus exhibit unique properties, which go on to influence the bonding interactions with adsorbates [21,22,27].

While it is well-known that a mineral's surface structure is transformed by contact with water, previous studies have investigated the interaction of flotation reagents with the surface modeled in the structure found under ultra-high vacuum conditions [28-31]. This may not be a realistic representation of the flotation process, as the reactivity of interest is actually occurring at a differently structured mineral-water interface. Therefore, the influence of water on the surface should also be investigated $[7,32,33]$. The quartz-water interface has been studied using molecular dynamics simulations (MDS), yielding information about how the surface was transformed by the presence of water [34-37]. However, a molecular-level understanding of the adsorption process and mechanism, such as that which can be attained through DFT modeling, is still lacking.

In this paper, DFT calculations are carried out on the $\mathrm{Si}$, O-middle, and O-rich terminations of a simulated (001) quartz surface. After each termination is geometry-optimized against a vacuum, the interaction of the most stable termination with water is investigated. The DFT results are analyzed in terms of energy, surface geometry, and electronic properties. As such, the information reported here contributes to a fundamental understanding of the ubiquitous quartz surface, which is of interest to those in the field of mineralogy as well as those interested in the many industrial applications of quartz. In particular, the results about the quartz-water interface are critical to understanding reagent adsorption and other surface-mediated processes occurring at the quartz-water interface.

\section{Computational Method and Model}

\subsection{Computational Method}

Calculations have been made using the Cambridge Serial Total Energy Package (CASTEP) [38] in the TCM Group of the Cavendish Laboratory in Cambridge, UK. CASTEP implements DFT using periodic boundary conditions and a planewave basis set [39]. Calculations in this study used ultrasoft pseudopotentials to model the electron-nucleus interactions at reduced computational cost [40]. The convergence tolerances for geometry optimization calculations were set to a maximum displacement of $0.002 \AA$, a maximum force of $0.05 \mathrm{eV} \cdot \AA^{-1}$, a maximum energy change of $2.0 \times 10^{-5} \mathrm{eV} \cdot$ atom $^{-1}$, and a maximum stress of $0.1 \mathrm{GPa}$, and the SCF convergence tolerance was set to be $2.0 \times 10^{-6} \mathrm{eV} \cdot \mathrm{atom}^{-1}$. 
The valence electron configurations considered in the work are $\mathrm{Si} 3 \mathrm{~s}^{2} 3 \mathrm{p}^{2}, \mathrm{O} 2 \mathrm{~s}^{2} 2 \mathrm{p}^{4}$, and $\mathrm{H} 1 \mathrm{~s}^{1}$. Before adsorption, the $\mathrm{H}_{2} \mathrm{O}$ was placed inside a $10 \AA \times 10 \AA \times 10 \AA$ cubic cell for an optimization calculation. Computational parameters such as the planewave basis set cutoff energy and k-point sample were tested for convergence.

\subsection{Quartz Crystal Cell Optimization}

The quartz crystal space group $\mathrm{D}_{3}^{6}-\mathrm{P}_{2} 21$ belongs to a rhombohedral system with the starting unit cell parameters of $\mathrm{a}=\mathrm{b}=4.973 \AA, \mathrm{c}=5.469 \AA, \alpha=\beta=90.0^{\circ}$, and $\gamma=120.0^{\circ}$ (see Figure 1). It is comprised of the structures of silicon oxygen tetrahedron, and the silicon atom was located at the tetrahedron center. Each silicon atom was coordinated with four oxygen atoms. The angles of O-Si-O were $110.1^{\circ}$ and $108.7^{\circ}$, and the bond lengths of $\mathrm{Si}-\mathrm{O}$ were $1.620 \AA$ and $1.624 \AA$.
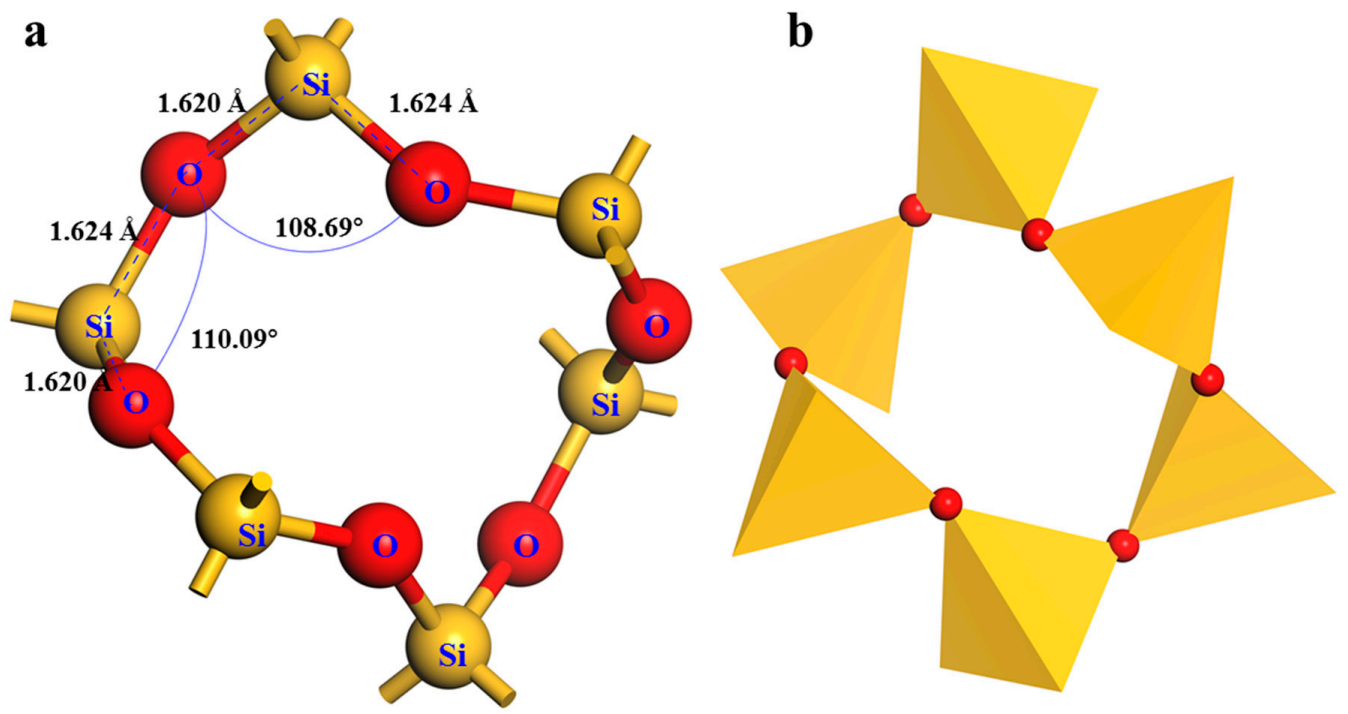

Figure 1. The cell model of quartz: (a) ball and stick model; (b) polyhedron model.

A bulk quartz cell was modeled to form a basis for the subsequent surface calculations. The dependence of the rationality of the quartz unit-cell on exchange-correlation functionals selection, the k-point set mesh, and cutoff energy was tested. Afterwards, the calculated crystal lattice parameters were compared with experimental values to determine the validity of the computed quartz crystal cell. After geometry optimization, the exchange correlation functional used was the generalized gradient approximation (GGA) developed via the Perdew-Wang generalized-gradient approximation (PW91) [41], and kinetic energy cutoff was set at $360 \mathrm{eV}$, and a $5 \times 5 \times 4$ grid was chosen for all structure calculations. The quartz cell parameters obtained after minimization were $a=b=4.964 \AA$, $c=5.470 \AA$, with deviations of $0.14 \%$ and $0.02 \%$, respectively, compared with experiment values [42]. This showed that the calculation conditions chosen were sufficient for the system, and the method was credible for the subsequent calculations. More detailed data for the above geometry optimization of bulk cell is provided in the supplementary material.

\subsection{Surface Models and Calculation of Surface Energy}

The quartz (001) surface was cleaved on the basis of an optimized $1 \times 1$ bulk structure. The (001) cleave plane forms three different exposed atoms, as shown in Figure 2. The cleaved surfaces are formed by breaking $\mathrm{Si}-\mathrm{O}$ bonds to generate highly reactive $\mathrm{Si}$ and $\mathrm{Si}-\mathrm{O}$ free radical species. The $\mathrm{Si}$ termination exposes a single silicon atom with double coordination bonds (Figure 2a), the O-middle termination exposes an oxygen atom with a single coordination and a silicon atom with three coordination bonds (Figure 2b), and the O-rich termination exposes two oxygen atoms both with a single coordination 
bonded with the first silicon atom with four coordination bonds (Figure $2 \mathrm{c})$. The $(1 \times 1)$ terminations were used to test for a suitable number of atomic layers to create the slab model and to determine a sufficient vacuum thickness to prevent interactions between periodic images in the direction of the surface normal. For both the surface slab models and the $\mathrm{H}_{2} \mathrm{O}$ molecule adsorption surface, the eight outermost atomic layers of the substrate were allowed to relax, while the 10 bottom-most atomic layers of the substrate were fixed to the bulk coordinates.

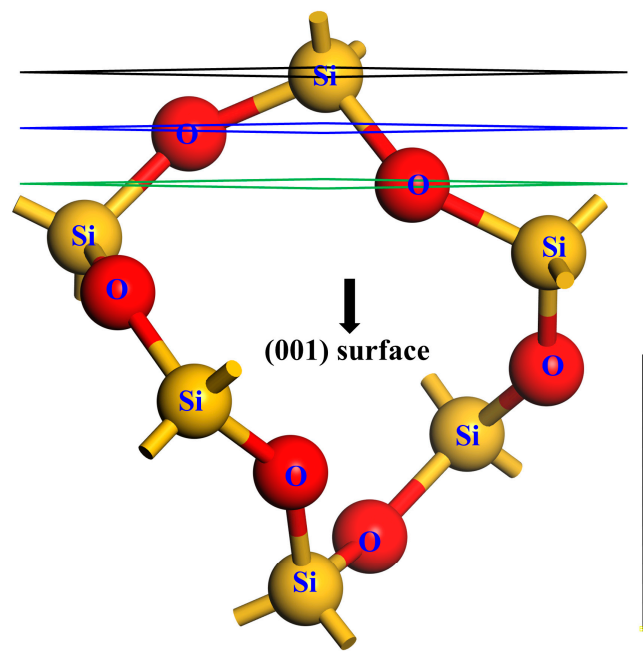

a. Si termination

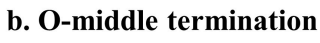

c. O-rich termination

Figure 2. Three typical exposed atom terminations when cleaving the quartz (001) surface (the lines of $(\mathbf{a}-\mathbf{c})$ represent the terminal atomic layers of the modeled surfaces).

The surface energy $\left(E_{\text {surf }}\right)$ is the required energy to cleave the crystal into two independent surfaces in the crystal direction of the crystal cleavage under the action of external force, which is dependent on the interaction of surface atoms and closely related with the geometrical structure of the surface atoms. For surface systems without external force, the total surface energy of the system tends to be minimized. The $E_{\text {surf }}$ of creating the cleaved surface can be estimated by the following relation [27]:

$$
E_{\text {surf }}=\left(E_{\text {slab }}-N \cdot E_{\text {bulk }}\right) / 2 S
$$

where $E_{\text {slab }}$ is the energy of the corresponding slab; $E_{\text {bulk }}$ is the energy of bulk crystal; $N$ is the number of bulk units in the slab; $S$ is the surface area of cell. The smaller the surface energy is, the higher the surface stability is.

It is quite necessary to test the atomic layer number and vacuum thickness to obtain the relative stable surface models of different terminations. Tables 1 and 2 show the influence of the atomic layer number and vacuum thickness on the surface energy of three different terminations of the quartz (001) surface, respectively.

Table 1. Effects of atomic layer number on surface energy of different terminations of the quartz (001) surface (the vacuum thickness in these tests was set at $10 \AA$ ).

\begin{tabular}{cccc}
\hline \multirow{2}{*}{ Atomic Layer Number } & \multicolumn{3}{c}{ Surface Energy/(J·m $\mathbf{m}^{-\mathbf{2}} \mathbf{~}$} \\
\cline { 2 - 4 } & Si Termination & O-Middle Termination & O-Rich Termination \\
\hline 9 & 2.928 & 1.999 & 2.920 \\
12 & 3.124 & 2.000 & 2.915 \\
15 & 2.898 & 1.997 & 2.907 \\
18 & 2.896 & 1.995 & 2.896 \\
21 & 2.896 & 1.995 & 2.893 \\
24 & 2.897 & 1.999 & 2.899 \\
\hline
\end{tabular}


Table 2. Effects of vacuum thickness on surface energy of different terminations of the quartz (001) surface (the atomic layer number in these tests was set at 18).

\begin{tabular}{|c|c|c|c|}
\hline \multirow{2}{*}{ Vacuum Thickness/Å } & \multicolumn{3}{|c|}{ Surface Energy $/\left(\mathrm{J} \cdot \mathrm{m}^{-2}\right)$} \\
\hline & Si Termination & O-Middle Termination & O-Rich Termination \\
\hline 8 & 2.905 & 1.986 & 2.894 \\
\hline 10 & 2.896 & 1.995 & 2.896 \\
\hline 15 & 2.896 & 1.969 & 2.892 \\
\hline 18 & 2.899 & 1.969 & 2.894 \\
\hline 20 & 2.894 & 1.972 & 2.892 \\
\hline
\end{tabular}

From the results of Tables 1 and 2, it is obvious that the changes in surface energy for the different terminations are not very noticeable after simulation, which indicates that the testing range of the atomic layer number and vacuum layer thickness set in the calculation were reasonable, and the three terminations all showed a certain stability. For all of the surface terminations, it was determined that 18 atomic layers and $15 \AA$ of vacuum is sufficient to converge the calculated surface energy. Based on convergence studies, structures for the three different surface terminations of quartz (001) were generated, as shown in Figure 3, with the atomic layers identified.
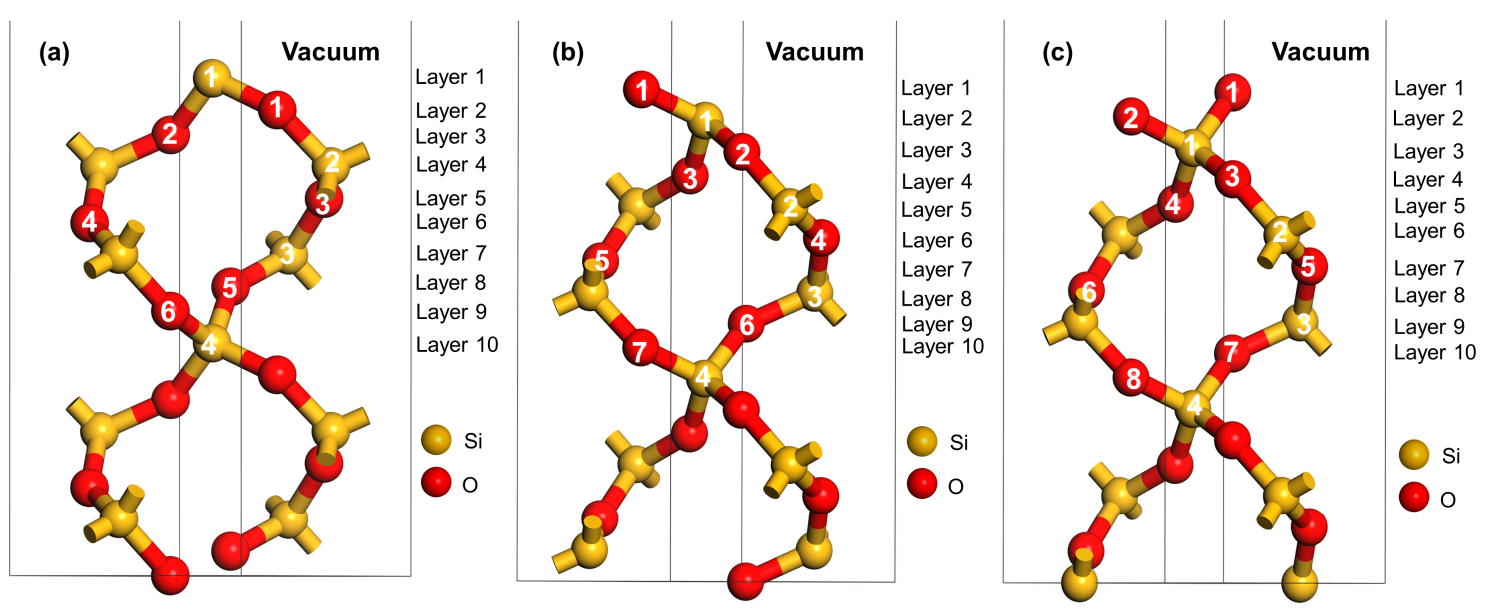

Figure 3. Side views of the three different slab models of the quartz (001) surface: (a) Si termination,

(b) O-middle termination, and (c) O-rich termination.

\section{Results and Discussion}

\subsection{Surface Structural and Electronic Properties of Different Terminations for Quartz (001) Surface}

\subsubsection{Surface Energy}

It is generally known that the lower the surface energy is, the more stable the surface is [21]. Among the three terminations, the O-middle termination has the lowest surface energy at $1.969 \mathrm{~J} \cdot \mathrm{m}^{-2}$. Cleaving on this termination needs less energy than that of any other surfaces, which indicates that it is likely to be the most stable termination model of the quartz (001) surface by DFT calculation. The surface energies of Si termination and O-rich termination are higher at $2.896 \mathrm{~J} \cdot \mathrm{m}^{-2}$ and $2.892 \mathrm{~J} \cdot \mathrm{m}^{-2}$, respectively, showing the consistent surface stability. The DFT calculated values for the surface energy provides some guidance as to what surface termination is the most thermodynamically stable. However, as the DFT total energies are modeled at $0 \mathrm{~K}$, effects such as temperature and pressure are neglected. Furthermore, it is possible that, in the real system, metastable surface terminations may be kinetically stabilized. Therefore, there are practical limitations to the interpretation of the DFT predictions based on the surface energies. Next, we calculated the surface relaxation, surface atomic 
Mulliken charge distribution, Mulliken bond population, and density of states to further investigate the property differences of the three terminations.

\subsubsection{Surface Relaxation}

In going from the bulk to a surface structure, the coordination number of the exposed atoms changes, and it is expected that the outermost atoms will undergo inward relaxations to recover a stable bonding environment. This is called the relaxation of minerals surface atoms. The relaxation formula is as follows [22]:

$$
\Delta Z=\frac{Z_{i}-Z_{i, b u l k}}{a} \times 100 \%
$$

where the $Z_{i}$ represents the corresponding atomic coordinate of $S i$ and $\mathrm{O}$ atoms in the $i$-th layer after the relaxation; $Z_{i}$, bulk denotes the bulk atomic coordinate of $S i$ and $\mathrm{O}$ atoms in the $i$-th layer, which was established by the bulk of quartz after the geometry optimization; $a$ refers to the bulk lattice parameter along the $z$-axis before geometry optimization.

The atomic displacements and coordination of three different terminations of the quartz (001) surface are given in Table 3. The displacements of surface silicon and oxygen atoms in the top three layers changed in variety after relaxation duo to the dangling bond on the surface. They move toward or away from the bulk in the direction of the $x-, y$-, and $z$-axes. In the special ring structure of the silicon oxygen tetrahedron of quartz, the atoms of the top three layers show a certain stretching effect on the atoms under them, with the result that some atoms in the bulk layer that bonded with them also have different degrees of contraction relaxation. The surface structure of different terminations before and after relaxation from the same side view are shown in Figure 4 as the direct display of relaxation results.

Table 3. Atomic displacement and coordination of different terminations of the quartz $(001)$ surface $\left(\mathrm{C}^{*}\right.$ represents the coordination number of atoms).

\begin{tabular}{ccccccccccccc}
\hline \multirow{2}{*}{ Atoms } & \multicolumn{3}{c}{ Si Termination } & \multicolumn{4}{c}{ O-Middle Termination } & \multicolumn{3}{c}{ O-Rich Termination } \\
\cline { 2 - 13 } & $\mathbf{C}^{*}$ & $\Delta \boldsymbol{x}$ & $\Delta \boldsymbol{y}$ & $\Delta \boldsymbol{z}$ & $\mathbf{C}^{*}$ & $\Delta \boldsymbol{x}$ & $\Delta \boldsymbol{y}$ & $\Delta \boldsymbol{z}$ & $\mathbf{C}^{*}$ & $\Delta \boldsymbol{x}$ & $\Delta \boldsymbol{y}$ & $\Delta \boldsymbol{z}$ \\
\hline $\mathrm{O}_{1}$ & 2 & 0.12 & 0.07 & -0.02 & 1 & 0.07 & 0.05 & 0.20 & 1 & -2.24 & 0.06 & -0.11 \\
$\mathrm{O}_{2}$ & 2 & -0.11 & -0.21 & -0.01 & 2 & 0.58 & 0.17 & 0.05 & 1 & 2.11 & 0.49 & 0.21 \\
$\mathrm{O}_{3}$ & 2 & 0.12 & -0.03 & 0.03 & 2 & -0.10 & -0.29 & -0.05 & 2 & 0.40 & 0.69 & -0.35 \\
$\mathrm{O}_{4}$ & 2 & 0.06 & 0.04 & 0.01 & 2 & 0.26 & -0.30 & -0.04 & 2 & -0.77 & 0.02 & -0.21 \\
$\mathrm{O}_{5}$ & 2 & 0.03 & -0.11 & 0.06 & 2 & -0.01 & 0.00 & 0.04 & 2 & -0.25 & -0.46 & -0.22 \\
$\mathrm{O}_{6}$ & 2 & 0.11 & 0.04 & 0.03 & 2 & -0.05 & -0.32 & 0.04 & 2 & -0.40 & -0.17 & -0.08 \\
$\mathrm{O}_{7}$ & 2 & 0.05 & 0.08 & 0.01 & 2 & 0.20 & 0.20 & -0.03 & 2 & 0.33 & -0.61 & -0.12 \\
$\mathrm{O}_{8}$ & 2 & 0.41 & 0.22 & 0.09 & 2 & -0.01 & 0.03 & -0.05 & 2 & 0.63 & -0.04 & 0.11 \\
$\mathrm{Si}_{1}$ & 2 & -2.76 & -0.29 & 0.05 & 4 & -1.81 & -0.77 & -0.18 & 4 & -0.04 & 0.23 & -0.31 \\
$\mathrm{Si}_{2}$ & 4 & 0.08 & -0.06 & 0.00 & 4 & 0.19 & 0.02 & 0.01 & 4 & -0.23 & 0.07 & -0.22 \\
$\mathrm{Si}_{3}$ & 4 & 0.10 & -0.02 & 0.24 & 4 & 0.18 & -0.02 & 0.01 & 4 & 0.08 & -0.29 & -0.09 \\
$\mathrm{Si}_{4}$ & 4 & 0.13 & 0.02 & 0.05 & 4 & 0.18 & 0.02 & -0.01 & 4 & 0.20 & -0.05 & 0.05 \\
\hline
\end{tabular}



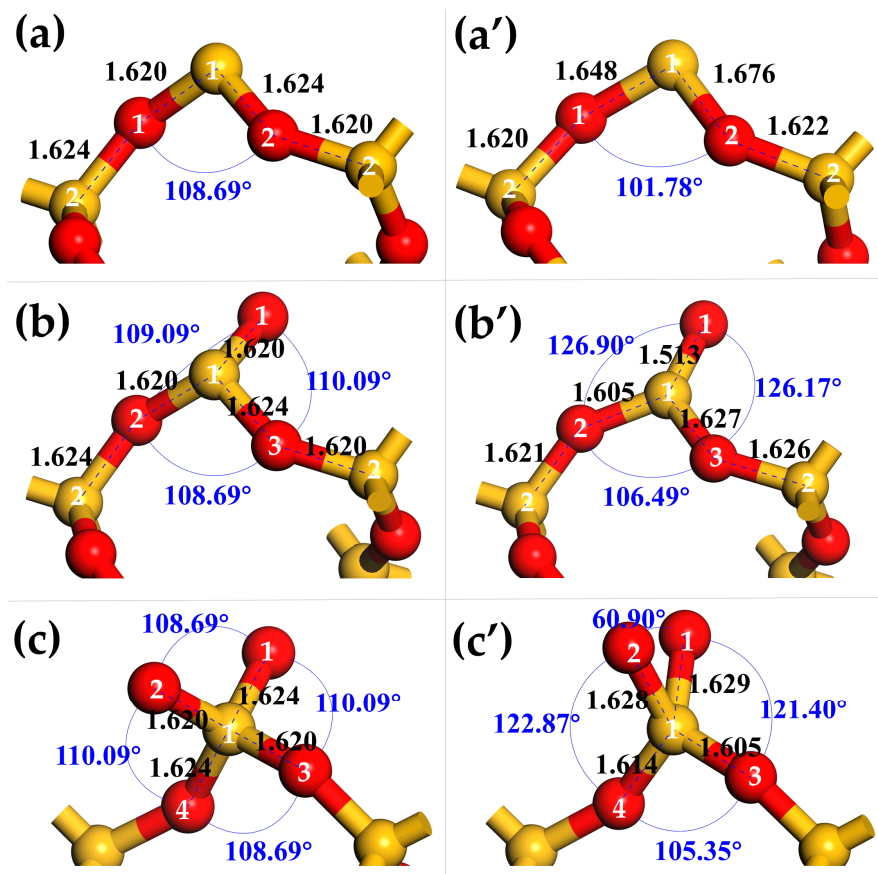

Figure 4. Surface structure of different terminations of the quartz (001) surface before and after relaxation from the same side view: (a) the surface structure of Si termination before relaxation; ( $\left.\mathbf{a}^{\prime}\right)$ the surface structure of $\mathrm{Si}$ termination after relaxation; $(\mathbf{b})$ the surface structure of O-middle termination before relaxation; $\left(\mathbf{b}^{\prime}\right)$ the surface structure of O-middle termination after relaxation; $(\mathbf{c})$ the surface structure of O-rich termination before relaxation; $\left(\mathbf{c}^{\prime}\right)$ the surface structure of O-rich termination after relaxation.

For the $\mathrm{Si}$ termination, the $\mathrm{Si}_{1}$ atom only shows a displacement along the $x$-axis $(-2.76 \%)$, and the overall structural relaxation degree is relatively low. This may be because the full ring structure of silicon oxygen tetrahedron show a strong binding and stretching effect on the $\mathrm{Si}$ atom in it. For the O-middle termination, the $\mathrm{O}_{1}$ and $\mathrm{Si}_{1}$ atoms have dangling bonds, and they show the reverse displacement along the $x$ - and $z$-axes. The first $\mathrm{O}_{1}$ atom has a small displacement along the $z$-axis at $0.20 \%$ away from the bulk, while the $\mathrm{Si}_{1}$ atom bonded with it has an opposite displacement along the $z$-axis at $-0.18 \%$ toward the bulk. Additionally, the $\mathrm{Si}_{1}$ atom also has a large displacement along the $x$-axis at $-1.81 \%$ and a slight displacement along the $y$-axis at $-0.77 \%$. The displacements of O-middle termination atoms are larger than that of $\mathrm{Si}$ termination. For the O-rich termination, the top $\mathrm{O}_{1}$ and $\mathrm{O}_{2}$ atoms have large displacements toward the opposite direction, and the major movement is along the $x$-axis direction (respectively at $-2.24 \%$ and at $2.11 \%$ ). The $\mathrm{O}_{2}$ atom also has a relative obvious displacement along the $y$-axis at $0.49 \%$ compared with that of the $\mathrm{O}_{1}$ atom at $0.06 \%$. Furthermore, the $\mathrm{O}_{1}$ and $\mathrm{O}_{2}$ atoms has a slight displacement along the $z$-axis, respectively, at $-0.11 \%$ for the $\mathrm{O}_{1}$ atom toward the bulk and $0.21 \%$ for the $\mathrm{O}_{2}$ atom away from the bulk. Over all, the O-rich termination is the most obvious one in all three terminations, and it can be seen directly from Figure 4 that the exposing two $\mathrm{O}$ atoms in double dangling $\mathrm{Si}-\mathrm{O}$ bonds show a larger angle rotation around the central $\mathrm{Si}_{1}$ atom, adjusting the spacing of the atoms and rearranging the electron distribution. The angles of $\mathrm{O}-\mathrm{Si}-\mathrm{O}$ on the surface changed substantially; in particular, the angle of $\mathrm{O}-\mathrm{Si}-\mathrm{O}$ decreased from $108.69^{\circ}$ to $60.90^{\circ}$.

\subsubsection{Surface Atomic Mulliken Charge Distribution}

In the Mulliken scheme of charge partitioning, the charges in the overlap region are distributed evenly between the relevant atomic orbitals. This is a relatively simple and effective method, but also has its shortcomings, since the charge apparently tends to be distributed to the atoms with high electronegativity in the actual process. Additionally, it is also pointless to compare the absolute values 
of the atomic Mulliken charge simply, as the Mulliken charge is quite sensitive to the chosen basis set, and different basis sets vary greatly [43]. Even so, the results obtained under the same basis set conditions still make sense when the relative values of the Mulliken atomic charges are compared, which has been widely used as an efficient method to describe the charge transfer and bond strengths between different atoms $[7,20,33,44]$. In this section, the Mulliken atomic charge populations of surface atoms in each termination are calculated and compared with those of the bulk (Table 4).

Table 4. Surface atomic Mulliken charge distribution of different terminations of the quartz (001) surface and bulk.

\begin{tabular}{cccccc}
\hline Atoms & & $\mathbf{s}$ & $\mathbf{p}$ & Total & Charge/e \\
\hline \multirow{2}{*}{ Bulk } & $\mathrm{Si}$ & 0.57 & 1.07 & 1.64 & +2.36 \\
& $\mathrm{O}$ & 1.83 & 5.35 & 7.18 & -1.18 \\
\hline \multirow{5}{*}{ Si termination } & $\mathrm{Si}_{1}$ & 1.66 & 1.14 & 2.80 & +1.20 \\
& $\mathrm{O}_{1}$ & 1.84 & 5.33 & 7.17 & -1.17 \\
& $\mathrm{O}_{2}$ & 1.84 & 5.33 & 7.17 & -1.17 \\
& $\mathrm{Si}_{2}$ & 0.57 & 1.09 & 1.66 & +2.34 \\
& $\mathrm{O}_{3}$ & 1.83 & 5.36 & 7.19 & -1.19 \\
\hline \multirow{5}{*}{ O-middle termination } & $\mathrm{O}_{1}$ & 1.94 & 5.10 & 7.04 & -1.04 \\
& $\mathrm{Si}_{1}$ & 0.59 & 1.21 & 1.80 & +2.20 \\
& $\mathrm{O}_{2}$ & 1.85 & 5.34 & 7.19 & -1.18 \\
& $\mathrm{O}_{3}$ & 1.83 & 5.34 & 7.17 & -1.18 \\
& $\mathrm{Si}_{2}$ & 0.57 & 1.06 & 1.63 & +2.37 \\
\hline & $\mathrm{O}_{1}$ & 1.95 & 4.67 & 6.62 & -0.63 \\
& $\mathrm{O}_{2}$ & 1.95 & 4.69 & 6.64 & -0.64 \\
& $\mathrm{Si}_{1}$ & 0.54 & 1.00 & 1.54 & +2.46 \\
& $\mathrm{O}_{3}$ & 1.83 & 5.36 & 7.19 & -1.19 \\
& $\mathrm{O}_{4}$ & 1.83 & 5.37 & 7.20 & -1.20 \\
\hline
\end{tabular}

It can be seen that the Mulliken atomic charges populations of $\mathrm{Si}$ and $\mathrm{O}$ atoms on the surface layers are different from the bulk after relaxation. For the Si termination, 2s and 2p states of the $\mathrm{Si}_{1}$ atom gain electrons from 0.57 to 1.66 and from 1.07 to 1.14, respectively, and the overall charge reduction 1.16 e varies from +2.36 to $+1.20 \mathrm{e}$, and the charges of the $\mathrm{O}_{1}$ and $\mathrm{O}_{2}$ atoms each reduce 0.01 e. For the $\mathrm{O}$-middle termination, the $\mathrm{O}_{1}$ atom gains electrons 0.11 at 2 s states and loses electrons 0.25 at $2 p$ states, respectively. The overall charge reduction 0.14 e varies from -1.18 e to $-1.04 \mathrm{e}$, while the overall charge of the $\mathrm{Si}$ atom reduction 0.16 e varies from +2.36 to +2.20 e. For the O-rich termination, the $\mathrm{O}_{1}$ and $\mathrm{O}_{2}$ atoms both lose electrons at $2 \mathrm{p}$ states, 0.68 and 0.66 , and the final charge reduces from -1.18 e to -0.63 e and -0.64 e, respectively. Furthermore, the charge of $\mathrm{Si}_{1}$ atom increases 0.1 e. It can be concluded that, for all the terminations, the electrons of surface-exposed atoms are redistributed due to the creation of dangling bonds relative to the bulk coordination.

\subsubsection{Surface Atomic Mulliken Bond Population}

It is well known, in general, that an ionic or covalent character can be determined according to Mulliken bond population. High populations indicate that the bond is covalent. On the contrary, low populations suggest that the interaction between bonds is ionic. Table 5 summarizes the Mulliken bond populations of the three terminations.

The Si-O population and length in the quartz bulk is about 0.52 and $1.624 \AA$, respectively, showing a covalence effect. The bond population and length of three terminations change to a certain extent due to the surface atomic charge transfer. For $\mathrm{Si}$ termination, as the charge of a $\mathrm{Si}_{1}$ atom gains $1.16 \mathrm{e}$, the $\mathrm{Si}_{1}-\mathrm{O}_{1}$ bond population reduces from 0.52 to 0.27 , and the length increases $0.052 \AA$, which indicates that the covalence of the $\mathrm{Si}-\mathrm{O}$ bond is weakened and ionicity is strengthened. For $\mathrm{O}$-middle termination, as the charge of the $\mathrm{O}_{1}$ atom and the $\mathrm{Si}_{1}$ atom is reduces by -0.14 e and +0.16 e, respectively, the $\mathrm{O}_{1}-\mathrm{Si}_{1}$ population increases from 0.52 to 0.96 with a 0.107 reduction in bond length, which indicates that the covalence interaction has been strengthened and the surface tends to be stable. For the O-rich 
termination, as $\mathrm{O}_{1}$ and $\mathrm{O}_{2}$ atoms do not lose many electrons, the $\mathrm{O}_{1}-\mathrm{Si}_{1}$ and $\mathrm{O}_{2}-\mathrm{Si}_{1}$ populations are reduced by 0.19 and 0.18 , with a 0.005 and 0.002 increase in bond length, indicating that the $\mathrm{O}-\mathrm{Si}$ covalent interactions weaken. Generally, the bonds near the surface mainly show extension compared with the bulk, which means that the ionicity between these atoms is enhanced due to the dangling bonds at the surface, and the results are in line with that of the tendency of the atomic displacements and surface charge distribution.

Table 5. Surface atomic Mulliken bond population of different terminations of the quartz (001) surface and bulk.

\begin{tabular}{cccc}
\hline Termination & Bond & Surface Population (Bulk) & Bond Length (Bulk)/Å \\
\hline \multirow{5}{*}{$\mathrm{Si}$} & $\mathrm{Si}_{1}-\mathrm{O}_{1}$ & $0.27(0.52)$ & $1.67(1.624)$ \\
& $\mathrm{Si}_{1}-\mathrm{O}_{2}$ & $0.52(0.53)$ & $1.61(1.632)$ \\
& $\mathrm{O}_{1}-\mathrm{Si}_{2}$ & $0.4(0.51)$ & $1.61(1.625)$ \\
& $\mathrm{O}_{2}-\mathrm{Si}_{2}$ & $0.5(0.63)$ & $1.62(1.622)$ \\
& $\mathrm{O}_{3}-\mathrm{Si}_{3}$ & $0.5(0.52)$ & $1.62(1.617)$ \\
\hline \multirow{5}{*}{ O-middle } & $\mathrm{O}_{1}-\mathrm{Si}_{1}$ & $0.9(0.52)$ & $1.51(1.620)$ \\
& $\mathrm{Si}_{1}-\mathrm{O}_{2}$ & $0.4(0.53)$ & $1.60(1.618)$ \\
& $\mathrm{Si}_{1}-\mathrm{O}_{3}$ & $0.4(0.53)$ & $1.62(1.628)$ \\
& $\mathrm{O}_{2}-\mathrm{Si}_{2}$ & $0.5(0.53)$ & $1.61(1.631)$ \\
& $\mathrm{O}_{3}-\mathrm{Si}_{2}$ & $0.5(0.52)$ & $1.62(1.624)$ \\
\hline \multirow{5}{*}{ O-rich } & $\mathrm{O}_{1}-\mathrm{Si}_{1}$ & $0.3(0.53)$ & $1.62(1.624)$ \\
& $\mathrm{O}_{2}-\mathrm{Si}_{1}$ & $0.3(0.52)$ & $1.62(1.626)$ \\
& $\mathrm{Si}_{1}-\mathrm{O}_{3}$ & $0.4(0.53)$ & $1.61(1.625)$ \\
& $\mathrm{Si}_{1}-\mathrm{O}_{4}$ & $0.5(0.53)$ & $1.61(1.625)$ \\
\hline
\end{tabular}

\subsubsection{Density of States}

Density of states (DOS) is one of the most important parameters for describing the states of motion of electrons in solid physics. In order to obtain a chemically intuitive description of the electronic structure, a state-by-state and atom-by-atom projected density of states (PDOS) analysis can be used. It has been widely used in solid physics, surface science, and interface absorption $[7,28,45,46]$. For further investigation, the PDOSs of the three terminations are shown in Figure 5. The PDOSs of surface $\mathrm{Si}$ and $\mathrm{O}$ atoms compared with that of the corresponding $\mathrm{Si}$ and $\mathrm{O}$ atoms in bulk are also presented in Figure 6 in order to reveal the surface properties of different terminations. The Fermi level $\left(\mathrm{E}_{\mathrm{F}}\right)$ is referenced at $0 \mathrm{eV}$. It has been reported that the region near the Fermi level is very important for various physical and chemical properties such as conductor type, reaction activity of surface atoms, and electrochemical potential of minerals [7,20,33]. Therefore, great attention has been paid to the details near the Fermi surface.

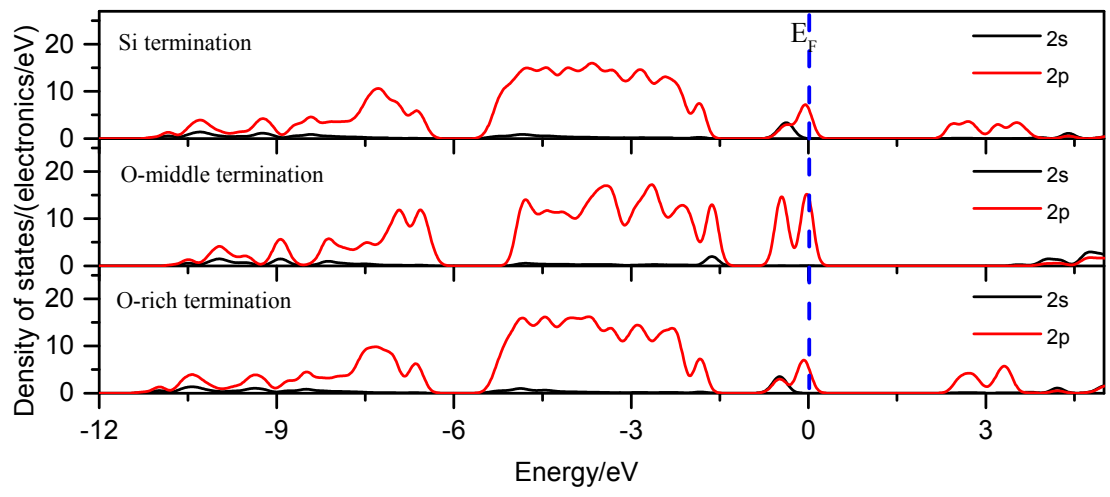

Figure 5. Projected density of states (PDOS) of three terminations of the quartz (001) surface. 


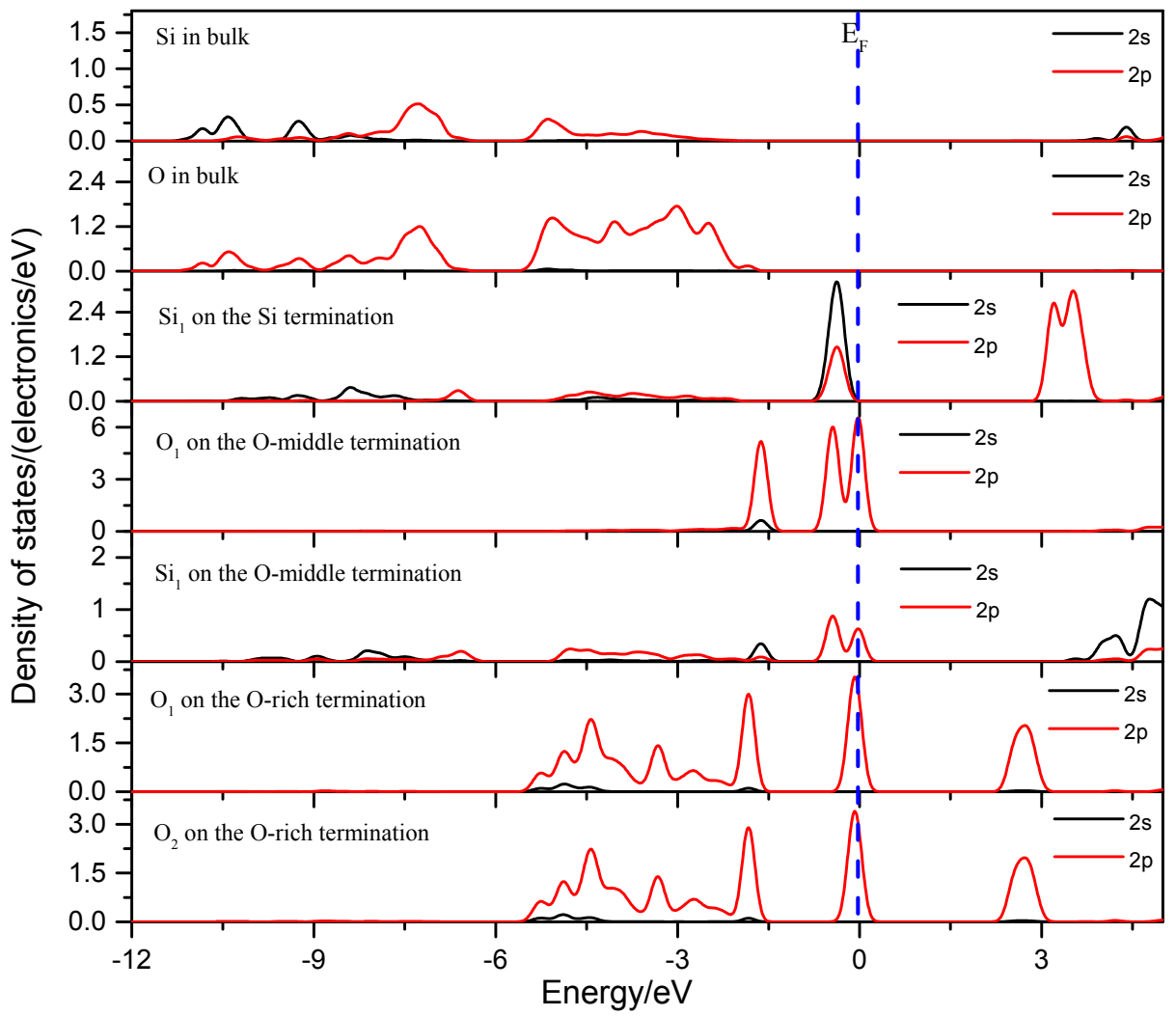

Figure 6. PDOSs of silicon and oxygen atoms on three terminations of the quartz (001) surface compared with that in bulk.

It is can be seen from Figure 5 that the energy range distributions of electrons for the three terminations are almost the same. For the quartz surface, the activity of electrons at $p$ states are much larger than that at s states, and the $\mathrm{p}$ states occupy the top of the valence band and the bottom of the conduction band, especially in the vicinity of the $\mathrm{E}_{\mathrm{F}}$ level. Overall, the activity of O-middle termination was greater than that of $\mathrm{Si}$ termination and O-rich termination when only considering the details near the Fermi surface, especially of the $2 p$ state electrons.

Figure 6 indicates that, for the $\mathrm{Si}$ termination, the $\mathrm{s}$ and $\mathrm{p}$ states of $\mathrm{Si}_{1}$ atoms occupy the vicinity of the $\mathrm{E}_{\mathrm{F}}$ level compared with that in the bulk; for the O-middle termination, the $\mathrm{p}$ states of $\mathrm{O}_{1}$ and $\mathrm{Si}_{1}$ atoms occupy in the vicinity of the $\mathrm{E}_{\mathrm{F}}$ level, and the contribution of $\mathrm{O}_{1}$ is much larger than the $\mathrm{Si}_{1}$ atom; for the O-rich terminations, the $\mathrm{p}$ states of the $\mathrm{O}_{1}$ and $\mathrm{O}_{2}$ atoms entirely occupy the vicinity of the $\mathrm{E}_{\mathrm{F}}$ level. Comparing the result of Figure 6 with Figure 5, we can see that the surface properties of different terminations are mainly formed by the surface-exposed atoms, as almost all contributions to $\mathrm{E}_{\mathrm{F}}$ in the DOS of the surface are made by the surface-exposed atoms, which is a conclusion consistent with studies about the electronic properties of fluorapatite (001) surfaces [21] and $\mathrm{AlCMn}_{3}$ (111) surfaces [22].

\subsection{Adsorption of an Isolated Water Molecule on Quartz (001) Surface}

The adsorption of an isolated $\mathrm{H}_{2} \mathrm{O}$ molecule on a quartz (001) surface was studied based on the most stable quartz (001) termination (O-middle termination). A $4 \times 3 \times 1$ supercell surface with atomic layer number 18 and vacuum thickness $18 \AA$ was built to accommodate the isolated $\mathrm{H}_{2} \mathrm{O}$ adsorption.

In terms of quartz surfaces, both the molecular and dissociative adsorptions have been considered based on research showing that the adsorption of water, depending on water coverage, can be either molecular or partially dissociative [25]. The optimized geometries are shown in Figures 7 and 8, where the yellow and red balls represent silicon and oxygen atoms of quartz, and the blue and light gray 
balls represent oxygen and hydrogen atoms of water; parts of atoms are displayed as lines in order to see the whole adsorption structure clearly in Figures $7 \mathrm{a}$ and $8 \mathrm{a}$, and the zoomed-in views of the $\mathrm{H}_{2} \mathrm{O}$ adsorption structure are shown in Figures $7 \mathrm{~b}$ and $8 \mathrm{~b}$; the bond length of newly formed bonds after adsorption are highlighted in blue, and the unit of bond length is $\AA$.
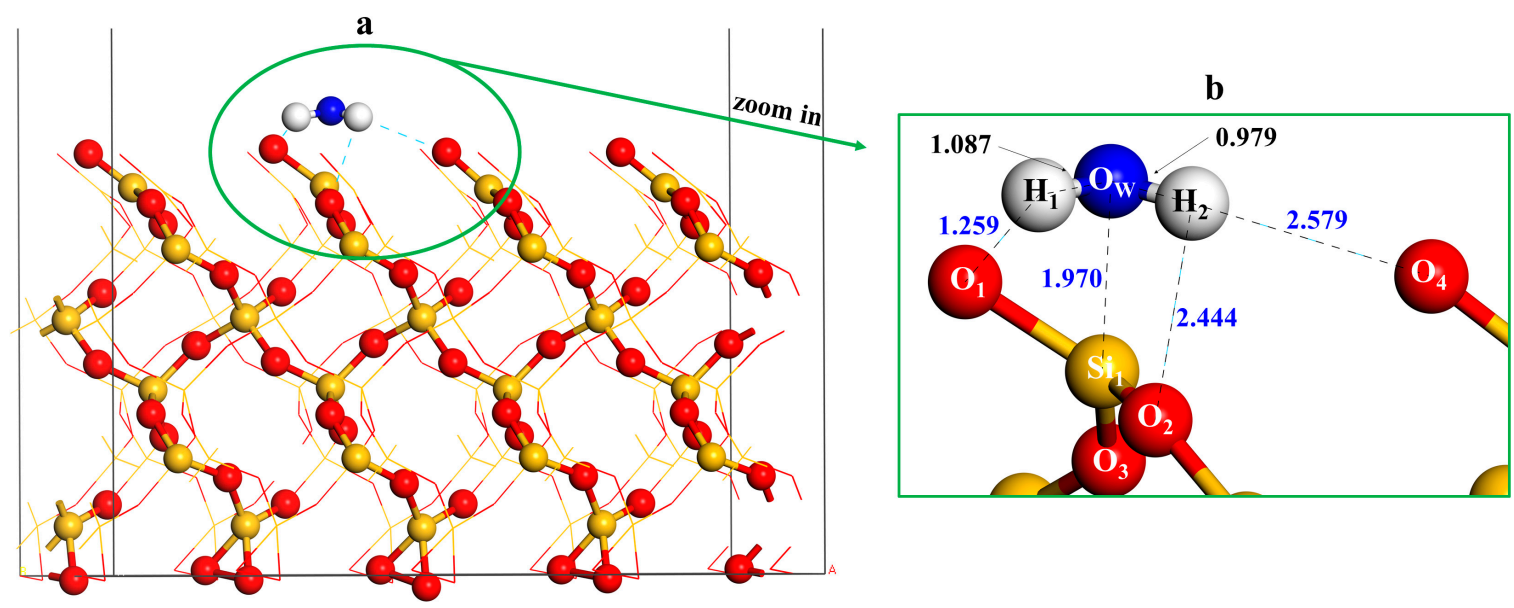

Figure 7. (a) Molecular adsorption model for $\mathrm{H}_{2} \mathrm{O}$ molecule on O-middle termination; (b) the zoomed-in view of the $\mathrm{H}_{2} \mathrm{O}$ adsorption structure.

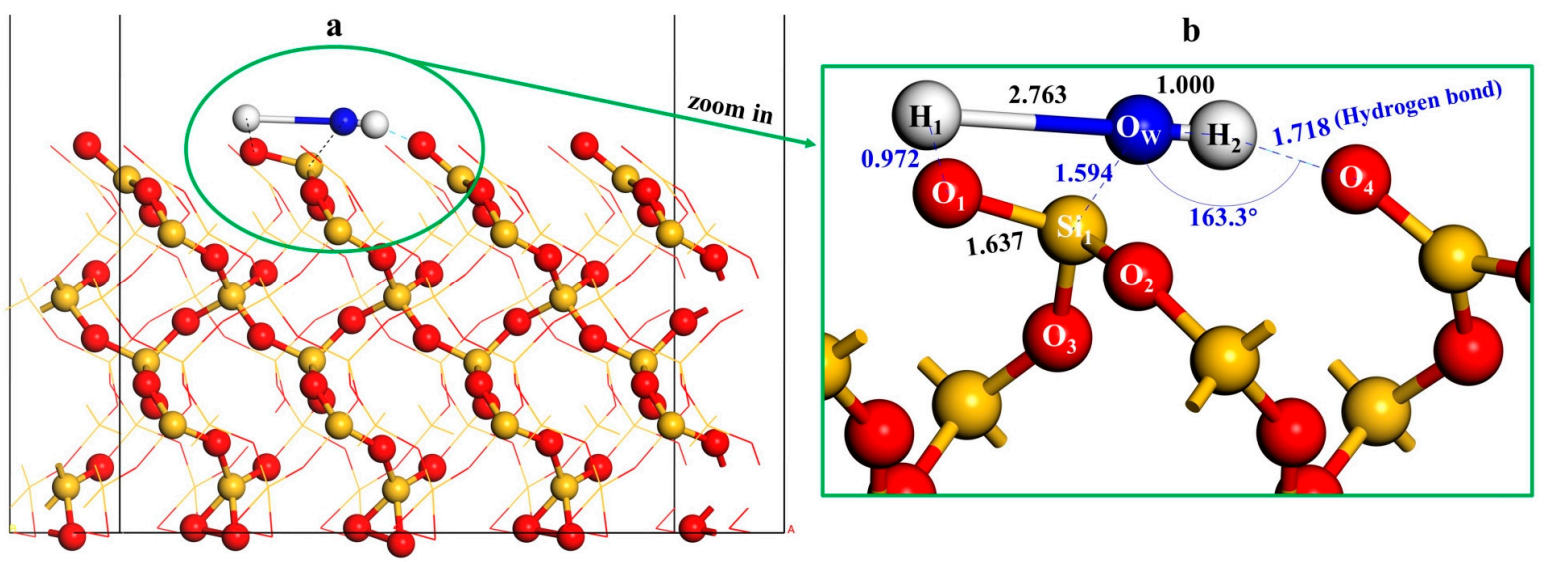

Figure 8. (a) Dissociative adsorption model for $\mathrm{H}_{2} \mathrm{O}$ molecule on O-middle termination; (b) the zoomed-in view of the $\mathrm{H}_{2} \mathrm{O}$ adsorption structure.

For the molecular adsorption, it was found that water prefers to adsorb on the surface $\mathrm{Si}$ and $\mathrm{O}$ atom mainly via $\mathrm{O}_{1}-\mathrm{H}_{1}$ bond at $1.259 \AA$ and $\mathrm{Si}_{1}-\mathrm{O}_{\mathrm{w}}$ at $1.970 \AA$. Furthermore, there are also two weak bonds $\mathrm{O}_{2}-\mathrm{H}_{2}$ at $2.444 \AA$ and $\mathrm{O}_{4}-\mathrm{H}_{2}$ at $2.579 \AA$ in the form of hydrogen bonds. The calculated adsorption energy of molecular adsorption is $600 \mathrm{meV} /$ molecule $\left(-57.89 \mathrm{~kJ} \cdot \mathrm{mol}^{-1}\right)$, mainly contributed by the Van der Waals force and weak hydrogen bond, which is close to the result of $618.9 \mathrm{meV}$ derived from the plane-wave-based Vienna ab initio Simulation Package (VASP) calculation in [47] and is comparable with hydrogen bonds between water molecules in Ice-XI bulk $(\sim 710 \mathrm{meV} /$ molecule in DFT [48] and $\sim 610 \mathrm{meV} /$ molecule in experiment [49]). Compared with other minerals, the adsorption energy is substantially larger than that of $-29.1 \mathrm{~kJ} \cdot \mathrm{mol}^{-1}$ on a hydrophobic galena surface and agrees well with that of $-56.2 \mathrm{~kJ} \cdot \mathrm{mol}^{-1}$ on a hydrophilic pyrite surface by DFT [32].

For the dissociative adsorption model, the structure of $\mathrm{Si}$ termination is quite different from the previous relaxed surface after adsorption. As we can see, the $\mathrm{H}_{2} \mathrm{O}$ molecule dissociates into $\mathrm{H}^{+}$and $\mathrm{OH}^{-}$bonded with the $\mathrm{O}_{1}$ and $\mathrm{Si}_{1}$ atoms, respectively, generating two new $\mathrm{Si}-\mathrm{OH}$ silanol groups on the quartz surface. At the same time, the $\mathrm{Si}_{1}-\mathrm{O}_{\mathrm{w}} \mathrm{H}_{2}$ group is bonded with the $\mathrm{O}_{4}$ atom 
forming the $\mathrm{O}_{\mathrm{w}} \mathrm{H}_{2} \cdots \mathrm{O}_{4}$ hydrogen bond. This indicates that the surface of quartz can be hydroxylated after adsorption of the $\mathrm{H}_{2} \mathrm{O}$ molecule, and the hydroxylation was also reported on the quartz (101) surface [50] and a single methanol molecule in water [51] by DFT. The calculated adsorption energy of dissociative adsorption is $1.03 \mathrm{eV} /$ molecule $\left(-99.37 \mathrm{~kJ} \cdot \mathrm{mol}^{-1}\right)$, mainly contributed by the chemical bond of new $\mathrm{Si}-\mathrm{OH}$ silanol groups and hydrogen bond. This energy is greater than that of $-82.4 \mathrm{~kJ} \cdot \mathrm{mol}^{-1}$ on hydrophilic pyrite surface by DFT [32]. In order to reveal the electron transfer and covalent interaction of new formed bonds after $\mathrm{H}_{2} \mathrm{O}$ molecule dissociative adsorption, the surface atomic Mulliken charge distribution and surface Mulliken bond population before and after adsorption of $\mathrm{H}_{2} \mathrm{O}$ were analyzed as shown in Tables 6 and 7 (the atomic numbers correspond to the labels in Figure 8).

Table 6. Surface atomic Mulliken charge distribution of O-middle termination before and after $\mathrm{H}_{2} \mathrm{O}$ adsorption.

\begin{tabular}{cccccc}
\hline Atom & Adsorption & $\mathbf{s}$ & $\mathbf{p}$ & Total & Charge/e \\
\hline \multirow{2}{*}{$\mathrm{H}_{1}$} & Before & 0.48 & 0 & 0.48 & 0.52 \\
& After & 0.46 & 0 & 0.46 & 0.54 \\
\hline \multirow{2}{*}{$\mathrm{H}_{2}$} & Before & 0.48 & 0 & 0.48 & 0.52 \\
& After & 0.50 & 0 & 0.50 & 0.50 \\
\hline \multirow{2}{*}{$\mathrm{O}_{\mathrm{w}}$} & Before & 1.89 & 5.15 & 7.05 & -1.05 \\
& After & 1.85 & 5.24 & 7.09 & -1.09 \\
\hline \multirow{2}{*}{$\mathrm{O}_{1}$} & Before & 1.94 & 5.10 & 7.04 & -1.04 \\
& After & 1.86 & 5.26 & 7.12 & -1.12 \\
\hline \multirow{2}{*}{$\mathrm{O}_{2}$} & Before & 1.85 & 5.34 & 7.19 & -1.18 \\
& After & 1.83 & 5.36 & 7.19 & -1.19 \\
\hline \multirow{2}{*}{$\mathrm{O}_{3}$} & Before & 1.83 & 5.34 & 7.17 & -1.18 \\
& After & 1.84 & 5.36 & 7.20 & -1.20 \\
\hline \multirow{2}{*}{$\mathrm{O}_{4}$} & Before & 1.94 & 5.10 & 7.04 & -1.04 \\
& After & 1.91 & 5.14 & 7.06 & -1.06 \\
\hline \multirow{2}{*}{$\mathrm{Si}_{1}$} & Before & 0.59 & 1.21 & 1.80 & 2.20 \\
& After & 0.58 & 1.05 & 1.63 & 2.37 \\
\hline
\end{tabular}

Table 7. Surface Mulliken bond populations of O-middle termination before and after $\mathrm{H}_{2} \mathrm{O}$ adsorption.

\begin{tabular}{ccccc}
\hline \multirow{2}{*}{ Bond } & \multicolumn{2}{c}{ Population } & \multicolumn{2}{c}{ Bond Length/ } \\
\cline { 2 - 5 } & Before & After & Before & After \\
\hline $\mathrm{Si}_{1}-\mathrm{O}_{1}$ & 0.96 & 0.51 & 1.513 & 1.637 \\
$\mathrm{Si}_{1}-\mathrm{O}_{2}$ & 0.42 & 0.45 & 1.600 & 1.630 \\
$\mathrm{Si}_{1}-\mathrm{O}_{3}$ & 0.43 & 0.45 & 1.625 & 1.645 \\
$\mathrm{O}_{\mathrm{w}}-\mathrm{H}_{2}$ & 0.51 & 0.53 & 0.978 & 1.000 \\
$\mathrm{Si}_{1}-\mathrm{O}_{\mathrm{w}}$ & - & 0.59 & - & 1.594 \\
$\mathrm{O}_{1}-\mathrm{H}_{1}$ & - & 0.54 & - & 0.972 \\
\hline
\end{tabular}

It can be seen from Table 6 that, after adsorption of $\mathrm{H}_{2} \mathrm{O}$, the electrons transfer from $\mathrm{Si}_{1}$ atoms to $\mathrm{O}_{1}$ and $\mathrm{O}_{\mathrm{w} 1}$ atoms. The $2 \mathrm{p}$ orbital of $\mathrm{O}_{1}$ and $\mathrm{O}_{\mathrm{w}}$ atoms gain electrons 0.16 and 0.09 , respectively, leading to their charge increasing from $-1.04 \mathrm{e}$ to $-1.12 \mathrm{e}$ and from $-1.05 \mathrm{e}$ to $-1.09 \mathrm{e}$. This indicates that the activities of $\mathrm{O}$ atoms in the two new $\mathrm{Si}-\mathrm{OH}$ silanol group are strengthened. The results of Table 7 show that, due to the new $\mathrm{Si}-\mathrm{OH}$ silanol group, the populations of $\mathrm{O}_{1}-\mathrm{Si}_{1}$ are reduced from 0.96 at the relaxation surface to 0.51 at the adsorption surface, which is almost equivalent to the bulk value 0.52 , indicating that the covalence of $\mathrm{Si}-\mathrm{O}$ bond is strengthened. The population of $\mathrm{Si}_{1}-\mathrm{O}_{\mathrm{w}}$ at 0.59 is higher than that of $\mathrm{Si}_{1}-\mathrm{O}_{1}$ at 0.51 , so the bond length of $\mathrm{Si}_{1}-\mathrm{O}_{1}$ is longer, suggesting that the two $\mathrm{Si}-\mathrm{OH}$ 
silanol groups are not completely consistent. The bond length of $\mathrm{O}_{\mathrm{w}}-\mathrm{O}_{4}$ is $2.690 \AA$ with an $\mathrm{H}_{2} \cdots \mathrm{O}_{4}$ length of $1.718 \AA$ and an $\mathrm{O}_{\mathrm{w}} \mathrm{H}_{2} \cdots \mathrm{O}_{4}$ angle of $163.03^{\circ}$, which is close to the reference hydrogen bond with an OO distance of $2.70 \AA$ after water adsorption on a quartz surface by VASP calculation [25]. The bond of $\mathrm{O}_{\mathrm{w}}-\mathrm{O}_{4}$ belongs to a strong hydrogen bond based on classification criterion (the strong one is within an OO distance of $2.72 \AA$ and an $\mathrm{OH} \cdots \mathrm{O}$ angle of $168^{\circ}$ ) originating from those reported in the 2D water layers on metal $\mathrm{Pt}$ (111) [52] and hydroxylated cristobalite (100) [53].

During bonding between two atoms, there are two types of bond orbitals-a bonding orbital and an antibonding orbital-that always appear in pairs. The bonding orbital is dominated by atomic orbitals with high electronegativity, whereas the antibonding orbital is dominated by atomic orbitals with low electronegativities [43]. To further investigate the bonding mechanism of $\mathrm{H}_{2} \mathrm{O}$ molecule after the dissociative adsorption, the PDOSs of $\mathrm{O}_{1}-\mathrm{H}_{1}$ bonding and $\mathrm{Si}_{1}-\mathrm{O}_{\mathrm{w}}$ bonding in the dissociative adsorption model are given in Figure 9.
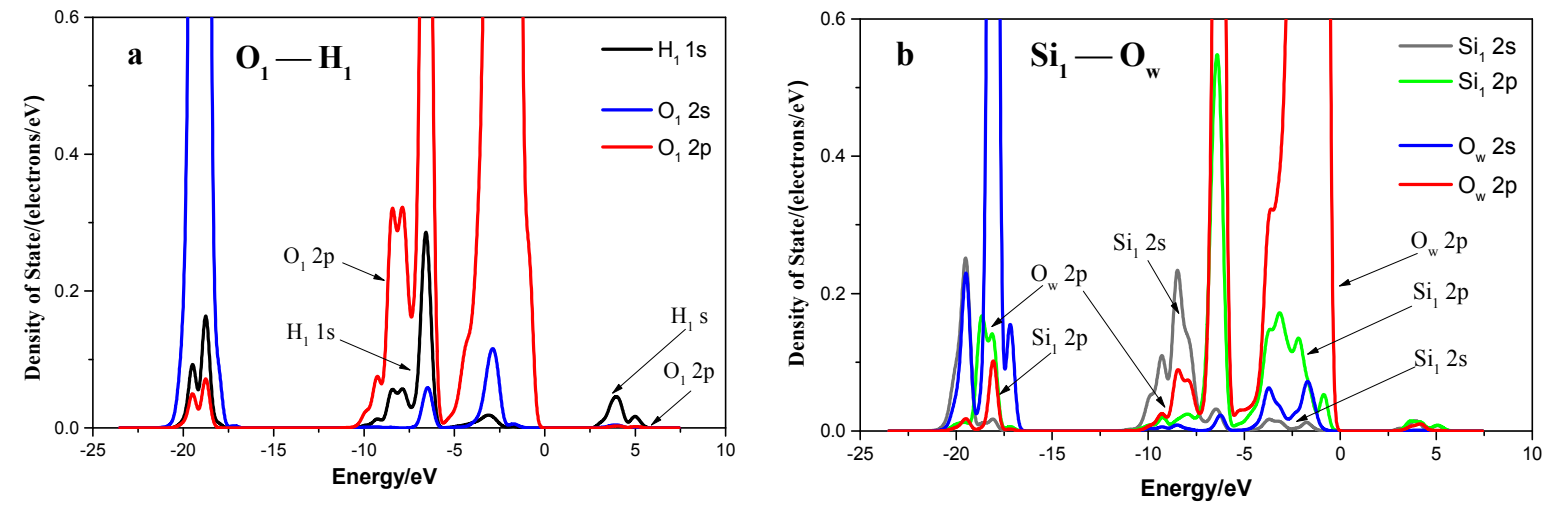

Figure 9. PDOSs of (a) $\mathrm{O}_{1}-\mathrm{H}_{1}$ bonding and (b) $\mathrm{Si}_{1}-\mathrm{O}_{\mathrm{w}}$ after the dissociative adsorption model for the $\mathrm{H}_{2} \mathrm{O}$ molecule on O-middle termination (in order to see the bonding energy clearly, parts of the PDOS peaks greater than 0.6 on the $y$-axis are not displayed).

Based on the PDOSs of $\mathrm{O}_{1}-\mathrm{H}_{1}$ bonding in Figure 9a, it can be clearly seen that the $\mathrm{O}_{1} 2 \mathrm{p}-\mathrm{H}_{1} 1 \mathrm{~s}$ bonding DOS peak appears between -1.5 and $-4.8 \mathrm{eV}$, and the antibonding DOS peak resonances are at $2.5-5.5 \mathrm{eV}$. The bonding effect is stronger than that of the antibonding bond. The bonding orbital has a quite wide energy level, indicating that the delocalization of electrons is high, which is also beneficial to bonding [28]. Additionally, the splitting effect of bonding and antibonding is quite large due to the whole energy $(-1.5-5.5 \mathrm{eV})$ across the Fermi level [54]. All of these both indicating that the bonding effect of $\mathrm{O}_{1}-\mathrm{H}_{1}$ is quite strong, mainly contributed by the $\mathrm{O}_{1} 2 \mathrm{p}-\mathrm{H}_{1}$ 1s. It is consistent with the Mulliken analysis results that the $\mathrm{O}_{1} 2 \mathrm{p}$ orbital gains electrons 0.16 and forms a strong $\mathrm{O}_{1}-\mathrm{H}_{1}$ bond with a length of $0.972 \AA$. Similarly, for the PDOSs of $\mathrm{Si}_{1}-\mathrm{O}_{\mathrm{w}}$ bonding in Figure $9 \mathrm{~b}$, the $\mathrm{Si}_{1}-\mathrm{O}_{\mathrm{w}}$ bond also showed a strong covalent interaction, mainly contributed by the $\mathrm{Si}_{1} 2 \mathrm{p}-\mathrm{O}_{\mathrm{w}} 2 \mathrm{p}$ with a bonding DOS peak between 0 and $-11.5 \mathrm{eV}$ and an antibonding DOS peak from -17.0 to $-21.0 \mathrm{eV}$, and the $\mathrm{Si}_{1}$ $2 \mathrm{~s}-\mathrm{O}_{\mathrm{w}} 2 \mathrm{p}$ with a bonding DOS peak between 0 and $-7.5 \mathrm{eV}$ and an antibonding DOS peak from -7.5 to $-11.0 \mathrm{eV}$. The results of the bonding DOS analysis are therefore in agreement with the analysis of Mulliken charge distribution and bond populations.

According to the adsorption energies in calculation, it is suggested that both the molecular adsorption and dissociative adsorption are favorable for isolated water molecules on the O-middle termination of a quartz (001) surface. The structure and electronic properties of the quartz surface are influenced by $\mathrm{H}_{2} \mathrm{O}$ molecule adsorption; that is, the reactivity site and the surface hydrophilic character changes. This is supported by a similar study on the relaxation and electronic structure of sulfide minerals surfaces in the presence of $\mathrm{H}_{2} \mathrm{O}$ molecules [55]. Thus, the adsorption of a flotation reagent at quartz-water interfaces would be different from that at a direct quartz surface without $\mathrm{H}_{2} \mathrm{O}$ 
interactions, which has already been identified in studies on thiol collector interaction on galena $(\mathrm{PbS})$ and sphalerite $(\mathrm{ZnS})$ in the presence of water molecules in DFT $[20,33]$.

\section{Conclusions}

DFT calculations were employed to investigate the structural and electronic properties of three distinct terminations of a (001) quartz surface, with subsequent water adsorption studies carried out on the surface that was predicted to be the most stable. It was found that a so-called O-middle termination, characterized by a single exposed oxygen atom at the surface, is most likely predominant in real samples, as it has the lowest associated surface energy. Water adsorption on the O-middle termination was therefore modeled. It is shown here that the structure and electronic properties of the surface are transformed by both molecular and dissociative water adsorption. Based on this information, it can be expected that exposure to a water environment will affect a quartz surface's structure and reactivity. Thus, the formation of the quartz-water interface must be accounted for when modeling processes, such as the flotation process, involve reagents. The results here provide valuable insight on how to represent the flotation process in a pulp environment through atomistic calculations.

Supplementary Materials: The following are available online at www.mdpi.com/xxx/s1: Table S1: Lattice constant and total energy of quartz conventional cell by using different exchange correlation (the cutoff energy and k-point were set at $340 \mathrm{eV}$ and $5 \times 5 \times 4$, respectively; Table S2: Lattice constant of quartz conventional cell by using different cutoff energy (the exchange correlation function and k-point were set at GGA-PW91 and $5 \times 5 \times 4$, respectively); Table S3: Lattice constant and band gap of quartz conventional cell by using different k-point (the exchange correlation function and cutoff energy were set at GGA-PW91 and $360 \mathrm{eV}$, respectively).

Acknowledgments: This research was financially supported by the National Natural Science Foundation of China (No. 51474078) and the Key Foundation of Science and Technology of Guizhou Province, China (No. Qian Ke He JZ [2014] 2009). Thanks are extended to Jianhua Chen and Baolin Ke from Guangxi University for their help in the molecular simulation study.

Author Contributions: Xianchen Wang and Qin Zhang conceived and designed the calculation models; Qin Zhang contributed the computation resources; Xianchen Wang performed all the calculations and wrote most of the manuscript. Xianbo Li, Junjian Ye and Longjiang Li participated in the data analysis and writing.

Conflicts of Interest: The authors declare no conflict of interest.

\section{References}

1. Su, J.W.; Esmaeilzadeh, H.; Zhang, F.; Yu, Q.; Cernigliaro, G.; Xu, J.; Sun, H.W. An ultrasensitive micropillar-based quartz crystal microbalance device for real-time measurement of protein immobilization and protein-protein interaction. Biosens. Bioelectron. 2018, 99, 325-331. [CrossRef] [PubMed]

2. Adam, S.; Koenig, M.; Rodenhausen, K.B.; Eichhorn, K.; Oertel, U.; Schubert, M.; Stamm, M.; Uhlmann, P. Quartz crystal microbalance with coupled spectroscopic ellipsometry-study of temperature-responsive polymer brush systems. Appl. Surf. Sci. 2017, 421, 843-851. [CrossRef]

3. Kim, B.; Jahng, J.; Khan, R.M.; Park, S.; Potma, E.O. Eigenmodes of a quartz tuning fork and their application to photoinduced force microscopy. Phys. Rev. B 2017, 95, 75440. [CrossRef]

4. Meng, Q.Y.; Yuan, Z.T.; Feng, Q.M.; Ou, L.M. The effect of quartz on the flotation of fine wolframite with octyl hydroxamic acid. Minerals 2017, 7, 186. [CrossRef]

5. Liu, A.; Fan, M.Q.; Fan, P.P. Interaction mechanism of miscible DDA-Kerosene and fine quartz and its effect on the reverse flotation of magnetic separation concentrate. Miner. Eng. 2014, 65, 41-50. [CrossRef]

6. Chen, Y.W.; Cheng, H.P. Structure and stability of thin water films on quartz surfaces. Appl. Phys. Lett. 2010, 97, 161909. [CrossRef]

7. Zhao, C.H.; Chen, J.H.; Li, Y.Q.; Huang, D.W.; Li, W.Z. DFT study of interactions between calcium hydroxyl ions and pyrite, marcasite, pyrrhotite surfaces. Appl. Surf. Sci. 2015, 355, 577-581. [CrossRef]

8. Liu, A.; Fan, M.; Li, Z.; Fan, J. Non-polar oil assisted DDA flotation of quartz I: Interfacial interaction between dodecane oil drop and mineral particle. Int. J. Miner. Process. 2017, 168, 1-8. [CrossRef]

9. Liu, A.; Fan, M.; Li, Z.; Fan, J. Non-polar oil assisted DDA flotation of quartz II: Effect of different polarity oil components on the flotation of quartz. Int. J. Miner. Process. 2017, 168, 25-34. [CrossRef] 
10. Li, X.B.; Zhang, Q.; Hou, B.; Ye, J.J.; Mao, S. Flotation separation of quartz from collophane using an amine collector and its adsorption mechanisms. Powder Technol. 2017, 318, 224-229. [CrossRef]

11. Ulusoy, U.; Yekeler, M.; Hiçyılmaz, C. Determination of the shape, morphological and wettability properties of quartz and their correlations. Miner. Eng. 2003, 16, 951-964. [CrossRef]

12. Luo, B.B.; Zhu, Y.M.; Sun, C.Y.; Li, Y.J.; Han, Y.X. Flotation and adsorption of a new collector $\alpha$-Bromodecanoic acid on quartz surface. Miner. Eng. 2015, 77, 86-92. [CrossRef]

13. Steurer, W.; Apfolter, A.; Koch, M.; Sarlat, T.; Søndergård, E.; Ernst, W.E.; Holst, B. The structure of the $\alpha$-quartz (0001) surface investigated using helium atom scattering and atomic force microscopy. Surf. Sci. 2007, 601, 4407-4411. [CrossRef]

14. Kawasaki, M.; Onuma, K.; Sunagawa, I. Morphological instabilities during growth of a rough interface: AFM observations of cobbles on the (0001) face of synthetic quartz crystals. J. Cryst. Growth 2003, 258, 188-196. [CrossRef]

15. Geatches, D.L.; Clark, S.J.; Greenwell, H.C. Role of clay minerals in Oil-Forming reactions. J. Phys. Chem. A 2010, 114, 3569-3575. [CrossRef] [PubMed]

16. Prigiobbe, V.; Negreira, A.S.; Lim, D.; Wilcox, J. Density functional theory calculations of the interaction of olivine with water. Energy Procedia 2013, 37, 5875-5883. [CrossRef]

17. Escamilla-Roa, E.; Huertas, F.; Hernández-Laguna, A.; Sainz-Díaz, C. A DFT study of the adsorption of glycine in the interlayer space of montmorillonite. Phys. Chem. Chem. Phys. 2017, 19, 14961-14971. [CrossRef] [PubMed]

18. Jung, J.E.; Liguori, S.; Jew, A.D.; Brown, G.E.J.; Wilcox, J. Theoretical and experimental investigations of mercury adsorption on hematite surfaces. J. Air Waste Manag. Assoc. 2018, 68, 39-53. [CrossRef] [PubMed]

19. Chen, Y.; Chen, J.H.; Guo, J. A DFT study on the effect of lattice impurities on the electronic structures and floatability of sphalerite. Miner. Eng. 2010, 23, 1120-1130. [CrossRef]

20. Long, X.H.; Chen, J.H.; Chen, Y. Adsorption of ethyl xanthate on ZnS (110) surface in the presence of water molecules: A DFT study. Appl. Surf. Sci. 2016, 370, 11-18. [CrossRef]

21. Qiu, Y.Q.; Cui, W.Y.; Li, L.J.; Ye, J.J.; Wang, J.; Zhang, Q. Structural, electronic properties with different terminations for fluorapatite (001) surface: A first-principles investigation. Comput. Mater. Sci. 2017, 126, 132-138. [CrossRef]

22. Wang, F.; Li, K.; Zhou, N.G. Structural, electronic properties and stability of $\mathrm{AlCMn}_{3}$ (111) surfaces by first-principles calculations. Appl. Surf. Sci. 2014, 289, 351-357. [CrossRef]

23. Chen, Y.W.; Cao, C.; Cheng, H.P. Finding stable $\alpha$-quartz (0001) surface structures via simulations. Appl. Phys. Lett. 2008, 93, 181911. [CrossRef]

24. Goumans, T.P.M.; Wander, A.; Brown, W.A.; Catlow, C.R.A. Structure and stability of the (001) $\alpha$-quartz surface. Phys. Chem. Chem. Phys. 2007, 9, 2146-2152. [CrossRef] [PubMed]

25. Yang, J.J.; Wang, E.G. Water adsorption on hydroxylated alpha-quartz (0001) surfaces: From monomer to flat bilayer. Phys. Rev. B 2006, 73, 035406. [CrossRef]

26. Wander, M.C.F.; Clark, A.E. Structural and dielectric properties of quartz-Water interfaces. J. Phys. Chem. C 2008, 112, 19986-19994. [CrossRef]

27. Wang, J.; Zhang, Q.; Qiu, Y.Q.; Li, L.J.; Ye, J.J.; Cui, W.Y. The first principles of the crystal structure and active sites of calcite. Chin. J. Eng. 2017, 39, 487-493.

28. Deng, J.S.; Wen, S.M.; Liu, J.; Wu, D.D.; Feng, Q.C. Adsorption and activation of copper ions on chalcopyrite surfaces: A new viewpoint of self-activation. Trans. Nonferrous Met. Soc. China 2014, 24, 3955-3963. [CrossRef]

29. Chen, J.H.; Lan, L.H.; Chen, Y. Computational simulation of adsorption and thermodynamic study of xanthate, dithiophosphate and dithiocarbamate on galena and pyrite surfaces. Miner. Eng. 2013, 46-47, 136-143. [CrossRef]

30. Chen, Y.; Chen, J.H. The first-principle study of the effect of lattice impurity on adsorption of $\mathrm{CN}$ on sphalerite surface. Miner. Eng. 2010, 23, 676-684. [CrossRef]

31. Chen, J.H.; Long, X.H.; Chen, Y. Comparison of multilayer water adsorption on the hydrophobic galena (PbS) and hydrophilic pyrite $\left(\mathrm{FeS}_{2}\right)$ surfaces: A DFT study. J. Phys. Chem. C 2014, 118, 11657-11665. [CrossRef]

32. Chen, J.H.; Long, X.H.; Zhao, C.H.; Kang, D.; Guo, J. DFT calculation on relaxation and electronic structure of sulfide minerals surfaces in presence of $\mathrm{H}_{2} \mathrm{O}$ molecule. J. Cent. South Univ. 2014, 21, 3945-3954. [CrossRef] 
33. Long, X.H.; Chen, Y.; Chen, J.H.; Xu, Z.H.; Liu, Q.X.; Du, Z. The effect of water molecules on the thiol collector interaction on the galena $(\mathrm{PbS})$ and sphalerite $(\mathrm{ZnS})$ surfaces: A DFT study. Appl. Surf. Sci. 2016, 389, 103-111. [CrossRef]

34. Rignanese, G.M.; Charlier, J.C.; Gonze, X. First-principles molecular-dynamics investigation of the hydration mechanisms of the (0001) $\alpha$-quartz surface. Phys. Chem. Chem. Phys. 2004, 6, 1920-1925. [CrossRef]

35. Du, Z.M.; de Leeuw, N.H. Molecular dynamics simulations of hydration, dissolution and nucleation processes at the $\alpha$-quartz (0001) surface in liquid water. Dalton Trans. 2006, 22, 2623-2634. [CrossRef] [PubMed]

36. Gor, G.Y.; Bernstein, N. Adsorption-Induced surface stresses of the Water/Quartz interface: Ab initio molecular dynamics study. Langmuir 2016, 32, 5259-5266. [CrossRef] [PubMed]

37. Notman, R.; Walsh, T.R. Molecular dynamics studies of the interactions of water and amino acid analogues with quartz surfaces. Langmuir 2009, 25, 1638-1644. [CrossRef] [PubMed]

38. Clark, S.J.; Segall, M.D.; Pickard, C.J.; Hasnip, P.J.; Probert, M.I.J.; Refson, K.; Payne, M.C. First principles methods using CASTEP. Zeitschrift für Kristallographie 2005, 220, 567-570. [CrossRef]

39. Vanderbilt, D. Soft self-consistent pseudopotentials in a generalized eigenvalue formalism. Phys. Rev. B 1990, 41, 7892-7895. [CrossRef]

40. Jones, R.O.; Gunnarsson, O. The density functional formalism, its applications and prospects. Rev. Mod. Phys. 1989, 61, 689-746. [CrossRef]

41. Perdew, J.P.; Chevary, J.A.; Vosko, S.H.; Jackson, K.A.; Pederson, M.R.; Singh, D.J.; Fiolhais, C. Atoms, molecules, solids, and surfaces: Applications of the generalized gradient approximation for exchange and correlation. Phys. Rev. B 1992, 46, 6671-6687. [CrossRef]

42. Kihara, K. An X-ray study of the temperature dependence of the quartz structure. Eur. J. Mineral. 1990, 2, 63-78. [CrossRef]

43. Chen, J.H. The Solid Physics of Sulphide Minerals Flotation; Central South University Press: Changsha, China, 2015.

44. Zhao, C.H.; Chen, J.H.; Long, X.H.; Guo, J. Study of $\mathrm{H}_{2} \mathrm{O}$ adsorption on sulfides surfaces and thermokinetic analysis. J. Ind. Eng. Chem. 2014, 20, 605-609. [CrossRef]

45. Chen, J.; Ke, B.; Lan, L.; Li, Y. Influence of Ag, Sb, Bi and Zn impurities on electrochemical and flotation behaviour of galena. Miner. Eng. 2015, 72, 10-16. [CrossRef]

46. Jiang, W.; Gao, Z.Y.; Sun, W.; Gao, J.; Hu, Y.H. A Density Functional Theory Study on the Effect of Lattice Impurities on the Electronic Structures and Reactivity of Fluorite. Minerals 2017, 7, 160. [CrossRef]

47. Chen, Y.W.; Chu, I.H.; Wang, Y.; Cheng, H.P. Water thin film-silica interaction on $\alpha$-quartz (0001) surfaces. Phys. Rev. B 2011, 84, 155444. [CrossRef]

48. Pan, D.; Liu, L.M.; Tribello, G.A.; Slater, B.; Michaelides, A.; Wang, E. Surface energy and surface proton order of ice Ih. Phys. Rev. Lett. 2008, 101, 155703. [CrossRef] [PubMed]

49. Feibelman, P.J. Partial dissociation of water. Science 2002, 295, 99-102. [CrossRef] [PubMed]

50. Woo, H.J.; David, S.S. Enantiospecific adsorption of amino acids on hydroxylated quartz (1010). Phys. Chem. Chem. Phys. 2010, 12, 8016-8023.

51. Van Erp, T.S.; Meijer, E.J. Hydration of methanol in water. A DFT-based molecular dynamics study. Chem. Phys. Lett. 2001, 333, 290-296. [CrossRef]

52. Meng, S.; Xu, L.F.; Wang, E.G.; Gao, S. Vibrational recognition of Hydrogen-Bonded water networks on a metal surface. Phys. Rev. Lett. 2002, 89, 176104. [CrossRef] [PubMed]

53. Yang, J.J.; Meng, S.; Xu, L.F.; Wang, E.G. Ice tessellation on a hydroxylated silica surface. Phys. Rev. Lett. 2004, 92, 146102. [CrossRef] [PubMed]

54. Li, Y.Q.; Chen, J.H.; Chen, Y.; Guo, J. Density functional theory study of influence of impurity on electronic properties and reactivity of pyrite. Trans. Nonferrous Met. Soc. 2011, 21, 1887-1895. [CrossRef]

55. Zhao, C.H.; Chen, J.H.; Wu, B.Z.; Long, X.H. Density functional theory study on natural hydrophobicity of sulfide surfaces. Trans. Nonferrous Met. Soc. 2014, 24, 491-498. [CrossRef]

(C) 2018 by the authors. Licensee MDPI, Basel, Switzerland. This article is an open access article distributed under the terms and conditions of the Creative Commons Attribution (CC BY) license (http://creativecommons.org/licenses/by/4.0/). 